American Journal of Biochemistry and Biotechnology 7 (1): 10-20, 2011

ISSN 1553-3468

(C) 2010 Science Publications

\title{
Relation between Macroscopic Binding Constant and the Anticancer Efficacy of the Bovine Serum Albumin-Quercetin Complex against Drug-Sensitive and Drug-Resistant Cells
}

\author{
${ }^{1}$ Winit Choiprasert, ${ }^{1}$ Chatchanok Loetchutinat, ${ }^{2}$ Nathupakorn Dechsupa and ${ }^{1}$ Samlee Mankhetkorn \\ ${ }^{1}$ Department of Radiologic Technology, Center of Excellence for Molecular Imaging, \\ Laboratory of Physical Chemistry, Molecular and Cellular Biology, \\ Faculty of Associated Medical Sciences, Chiang Mai University, Chiang Mai 50200, Thailand \\ ${ }^{2}$ Department of Radiologic Technology, Faculty of Associated Medical Sciences, \\ Chiang Mai University, Chiang Mai 50200, Thailand
}

\begin{abstract}
Problem statement: We have previously analyzed the interaction of BSA with flavonoids by using FRET. In this study, the role of BSA on increasing in solubility and on carrying the quercetin derivatives thus enhanced their anticancer efficacy against drug-sensitive and drug-resistant cells were conducted. Approach: The macroscopic $\left(\mathrm{K}_{\mathrm{D}}\right)$ and microscopic $\left(\mathrm{k}_{\mathrm{d}}\right)$ binding constant of the complexation and the cellular partition of molecules were analyzed using FRET and HPLC method, respectively. Results: The $\mathrm{K}_{\mathrm{D}}$ values reflex the stability of complexes was in the order of rutin $>$ quercetrin $>$ quercetin. BSA was a suitable carrier of quercetin $\left(\mathrm{K}_{\mathrm{D}}=1.68 \times 10^{5} \mathrm{M}^{-1}\right)$ which spontaneously release the molecule into solutions and cells. The substitution of rhamnoside $\left(\mathrm{K}_{\mathrm{D}}=\right.$ $\left.1.37 \times 10^{5} \mathrm{M}^{-1}\right)$ and rutinoside $\left(\mathrm{K}_{\mathrm{D}}=5.0 \times 10^{4} \mathrm{M}^{-1}\right)$ at $\mathrm{C} 3$ yielded an increase in stability of the complexes. Rutin was tightly bound to BSA resulting in the changes in mode of action. Conclusion: The macroscopic binding constant was directly influenced on the cellular uptake of molecules and the suitable range of binding constant was $\mathrm{K}_{\mathrm{D}} \geq 10^{5} \mathrm{M}^{-1}$ by which the carrier can be useful for increasing the solubility of drug and also spontaneously release the drug into the solution and cells.
\end{abstract}

Key words: Serum albumin, flavonoids, anticancer, Fluorescence Resonance Energy Transfer (FRET)

\section{INTRODUCTION}

Quercetin and its glycoside derivatives present great interest as potential anticancer and anticarcinogenic molecules are increasingly receiving interests due to their a variety of pharmacological activities including anti-inflammatory (Nijveldt et al., 2001; Wang et al., 2006), cardioprotective (Hirvonen et al., 2001; Knekt et al., 2002; Yochum et al., 1999; Hertog et al., 1997; Rimm et al., 1996; Mink et al., 2007) and cancer apoptosis induction activities (Samanta and Bhattacharya, 2010; Choiprasert et al., 2010; Kothan et al., 2004; Dechsupa et al., 2007; Li et al., 2007; Ramanouskaya et al., 2009). Despite the great interest in these compounds over the recent years, there is little data dealing with the physicochemical properties of molecule. In addition, the molecular based mechanisms of anticancer and its limiting step remains to be elucidate. Recently, Tungjai et al. (2008) reported the speciation of the molecule in physiological like solutions and determined the $\log \mathrm{P}$ value as well as the mean rate passive diffusion through the lipid bilayer membrane (Tungjai et al., 2008). These findings suggested that quercetin was passively diffused throughout the plasma membrane into the cytosolic site and the available cytosolic concentration of quercetin should be responsible for its specific anticancer action.

In fact these compounds are poorly soluble in water which limited their use in preclinical studies. It was known that lipids and proteins can considerable increase in the solubility of various drugs (Jones et al., 2008; Watanabe et al., 2008; Iwanaga et al., 2006). Many research groups have studied the in vivo consequences of binding of drugs and their metabolites to serum albumins (Lupidi et al., 2010; Yue et al., 2009). These researchers have examined the binding mechanisms of ligands with serum albumin by using absorption (Tian et al., 2004), fluorescence and voltammetric techniques (Kitson, 2004; Dufour and Dangles, 2005; Nia et al., 2009; Choiprasert and

Corresponding Author: Samlee Mankhetkorn, Department of Radiologic Technology, Laboratory of Physical Chemistry, Molecular and Cellular Biology, Center of Excellence for Molecular Imaging,

Faculty of Associated Medical Sciences, Chiang Mai University, Chiang Mai 50200, Thailand Tel: 6653949305 Fax. 6653213218 
Mankhetkorn, 2006). Based on these studies, the information on the binding processes of many exogenous ligands like long chain fatty acids, amino acids, drugs, bilirubin, etc. have been reported at the molecular level. These studies have also provided evidence that such binding can increase the solubility of ligands and thus increase its cytotoxicity. Contrary the binding of bilirubin to albumin caused a decreased its cytotoxicity (Jones et al., 2008; Watanabe et al., 2008; Iwanaga et al., 2006; Lupidi et al., 2010; Yue et al., 2009).

Serum albumins are abundantly found in blood plasma, circulate in the body several times and act as carriers for numerous exogenous and endogenous compounds (Varshney et al., 2010; Kratz, 2008). The most popularly studied albumins are Bovine Serum Albumin (BSA) and Human Serum Albumin (HSA). In general, albumins are characterized by low tryptophan and high cystine contents. BSA and HSA mainly differ in tryptophan content. Except for this, the amino acid compositions of the two proteins are nearly the same. HSA has one tryptophan group at the 214 position, while BSA has two tryptophan groups at 134 and 212 position (Moriyama et al., 1996; Mishra et al., 2005). Primarily, three domains and six principal binding sites have been identified for several important biomolecules. Both BSA and HSA have very high conformational adaptability to a great variety of legends.

The two serum albumins (HSA and BSA) have been shown to strongly bind quercetin and other structurally related flavonoids in vitro (Kitson, 2004; Dufour and Dangles, 2005; Nia et al., 2009; Choiprasert and Mankhetkorn, 2006). Dangles et al. (1999) and Dufour and Dangles (2005) quantitatively measured the binding constant $\left(\mathrm{K}_{\mathrm{D}}\right)$ of quercetin and its glycoside derivatives to BSA by using fluorescence spectroscopy, the determined $\mathrm{K}_{\mathrm{D}}$ values was equal to $8.6( \pm 1.1) \times 10^{5} \mathrm{M}^{-1}$ and $14.5( \pm 2.8) \times 10^{5} \mathrm{M}^{-1}$ for rutin and isoquercetrin, respectively. However, the correlation among the $\mathrm{K}_{\mathrm{D}}$ values, cellular partition and the anticancer activity of flavonoids has not been studied elsewhere.

In this study we have applied the FRET analyzed the complexation of BSA and quercetin derivatives. The macroscopic dissociation rate constant $\left(\mathrm{K}_{\mathrm{D}}\right)$ or the stability of complexes was in the order of rutin > quercetrin $>$ quercetin. BSA can be served as a carrier by which spontaneously release quercetin into solutions and cells. The substitution of rhamnoside and rutinoside at $\mathrm{C} 3$ yielded an increase in stability of the complexes. Rutin was tightly bound to BSA resulting in the changes in mode of action, probably mediated its cytotoxicic via an interaction with the extrinsic pathway, activated by pro-apoptotic receptor signals at the cellular surface.

A preliminary report of this work has been presented elsewhere (Choiprasert and Mankhetkorn, 2006).

\section{MATERIALS AND METHODS}

Quercetin $\quad\left(3,5,7,3^{\prime}, 4^{\prime}\right.$-Pentahydroxyflavone $)$, quercetin-3-rhamnoside or quercetrin (2-(3,4dihydroxyphenyl)-5,7-dihydroxy-3-[(2R,3R,4R,5R,6S)3,4,5-trihydroxy-6-methyloxan-2-yl] oxychromen-4one) and quercetin-3-rutinoside or rutin (3-[[6-O-(6Deoxy-alpha-l-mannopyranosyl)-beta-dglucopyranosyl]oxy]-2-(3,4-dihydroxy-phenyl)-5,7dihydroxy-4H-1-benzo-pyran-4-one) were purchased from Sigma. BSA-bovine fraction V (biotechnology grad) was from Amresco.

Pirarubicin stock solutions were prepared in water just before used. Concentrations were spectrophotometrically determined by diluting stock solutions in water to approximately $10 \mu \mathrm{M}$ and using $\varepsilon_{480}=11500 \mathrm{M}^{-1} \mathrm{~cm}^{-1}$. HEPES-Na ${ }^{+}$buffer consists of $20 \mathrm{mM}$ HEPES buffer plus $132 \mathrm{mM} \mathrm{NaCl}, 3.5 \mathrm{mM}$ $\mathrm{KCl}, 1 \mathrm{mM} \mathrm{CaCl} 2$ and $0.5 \mathrm{mM} \mathrm{MgCl}_{2}, \mathrm{pH} 7.25$ at $37^{\circ} \mathrm{C}$.

The absorption spectra were recorded on a Hewlett Packard HP 8435 spectrophotometer. Experiments were conducted in a $1 \mathrm{~cm}$ quartz cuvette containing $2 \mathrm{~mL}$ of solution under continuous stirring. The temperature was controlled at $37^{\circ} \mathrm{C}$ using a peltier temperature control, cell holder model 89090A.

Cell lines, cell culture and cytotoxicity assay: The human erythromyelogenous leukemic cell line (K562) and its DOX-resistant, P-glycoprotein-overexpressing K562/adr subline, (Choiprasert et al., 2010; Tungjai et al., 2008; Dechsupa and Mankhetkorn, 2009; Ayudhya and Mankhetkorn, 2009; Garnier-Suillerot et al., 2001) and the human small cell lung carcinoma cell line (GLC4) and its DOX-resistant, MRP1overexpressing GLC4/adr subline (Choiprasert et al., 2010; Tungjai et al., 2008) were routinely cultured in RPMI 1640 medium supplemented with $10 \%(\mathrm{v} / \mathrm{v})$ fetal calf serum in a humidified atmosphere with $5 \% \mathrm{CO}_{2}$ at $37^{\circ} \mathrm{C}$. For the cytotoxicity assays, cells were plated at a density of $5 \times 10^{5}$ cell. $\mathrm{mL}^{-1}$ and used $24 \mathrm{~h}$ later $\left(8 \times 10^{5}\right.$ cell $\mathrm{mL}^{-1}$ ) so that cells were in exponential growth phase. Cell viability was assessed by Trypan blue exclusion and cell number was determined with a haemocytometer. 
The cytotoxicity assays were performed as follows: cells $\left(5 \times 10^{4} \mathrm{~mL}^{-1}\right)$ were incubated in the presence of various concentrations of drugs. The number of cells was then determined by flow cytometry. The concentration of drug required to inhibit cell growth by $50 \%$ after $72 \mathrm{~h}\left(\mathrm{IC}_{50}\right)$ was determined by plotting the percentage of cell growth inhibition versus the drug concentration. The Resistance Factor (RF) was defined as the $\mathrm{IC}_{50}$ of resistant cells divided by the $\mathrm{IC}_{50}$ of the corresponding sensitive cells (Choiprasert et al., 2010; Kothan et al., 2004; Dechsupa and Mankhetkorn, 2009; Ayudhya and Mankhetkorn, 2009).

Cellular partition of compounds: Cells $\left(4 \times 10^{6} \mathrm{~mL}^{-1}\right)$ were incubated in the presence of $40 \mu \mathrm{M}$ of quercetin, quercetrin or rutin in RPMI 1640 supplemented with $10 \%(\mathrm{v} / \mathrm{v})$ fetal calf serum or HEPES-Na ${ }^{+}$buffered solution without or with $9 \mathrm{mg} \mathrm{mL}{ }^{-1}$ BSA pH 7.3 at $37^{\circ} \mathrm{C}$. The supernatant and cell pellets were separated at 1,3 and $6 \mathrm{~h}$ after incubation.

Sample preparation: Supernatant and pellets of cells were extracted twice with $5 \mathrm{~mL}$ of DMSO-Acetonitrile $(1: 4 \mathrm{v} / \mathrm{v})$ then centrifuged (NÜVE NF400, Turkey) at $4,400 \times \mathrm{g}$ for $10 \mathrm{~min}$. The acetonitrile fraction was collected and pooled together then dried using rotary evaporator and stored until HPLC analysis.

High Performance Liquid Chromatography (HPLC): The samples were analyzed using A SPDM20A High Performance Liquid Chromatography PDA detector (Shimadzu).

Spectrofluorometric measurements: Albumin of stock solution $1 \mathrm{mM}$ was dissolved in a HEPES-Na ${ }^{+}$ buffer $\mathrm{pH} 4$ and 7.3 at $37^{\circ} \mathrm{C}$. Steady-state fluorescence was recorded using a Perkin Elmer LS 50B spectrofluorometer. All studies were performed at $37^{\circ} \mathrm{C}$ using $2.5 \mathrm{~nm}$ and $5 \mathrm{~nm}$ excitation and emission slit widths, respectively. The emission signal of BSA was collected from 310-580 nm (excited at $310 \mathrm{~nm}$ ). Both of excitation-and emission-spectra of complexes were recorded at equilibrium state, a few minutes after addition the precised concentrations of flavonoids into BSA solution; the emission signal was collected from $460-580 \mathrm{~nm}$ (excited at $310 \mathrm{~nm}$ ).

\section{RESULTS}

Cellular uptake and metabolism of quercetin and its glycoside derivatives: Due to our long experiences on the cytotoxicty studied of flavonoids, it was observed that after adding varied concentration of quercetin ranging from 0.5-300 $\mu \mathrm{M}$ quercetin, quercetrin and rutin into the HEPES-Na ${ }^{+}$buffered solution $\mathrm{pH} 7.3$ at $37^{\circ} \mathrm{C}$, then the solutions were visualized under light microscope. At the concentration $\geq 100 \mu \mathrm{M}$, we observed crystalline homogeneously distributed throughout the bottom of well while the same did not observe in the presence of $9 \mathrm{mg} \mathrm{mL}^{-1}$ BSA. We also observed that the presence of quercetin and its glycoside derivatives in the 24 well-plate contained culture medium and cells appeared yellow-green color. The supernatant of cells was collected and spectrophotmetrically identified. The supernatants possessed an absorption spectrum between $320-500 \mathrm{~nm}$ with the maximum absorbance at $410 \mathrm{~nm}$. This absorption spectrum does not correspond to those of querctin, quertrin or rutin in $20 \mathrm{mM}$ HEPES-Na ${ }^{+}$buffer, $\mathrm{pH} 7.25$ at $37^{\circ} \mathrm{C}$. In fact, this difference was caused by the presence of plasma proteins since the supernatants were separated using $10 \%$ acrilamide gel electrophoresis and read by using FRET clearly demonstrated a band corresponding the BSA-flavonoid complex.

The uptake of the three molecules by $\mathrm{K} 562$, K562/adr, GLC4 and GLC4/adr cell were thus performed both by using the RPMI 1640 culture medium completed with $10 \%$ fetal calf serum and $1 \%$ penicillinstreptomycin (exactly the same conditions with the cytotoxicity assay) and HEPES-Na ${ }^{+}$buffer solution.

The typical results of quercetin partitioned into the cell pellets as a function of time was shown Fig. 1. As can be seen in Fig. 1a, the pattern of the amount of quercetin partitioned into the drug-sensitive cell was similar to those of drug-resistant cell pellets. The cellquercetin concentration increased with incremental incubation time in RPMI 1640 medium. The cellquercetin concentration was $15 \pm 7$ nmole (per $4 \times 10^{6}$ cells) at 6 hours after incubation in the four cell lines. It should be noted that when in HEPES- $\mathrm{Na}^{+}$buffered solution, an increase in quercetin concentration of cell pellets as a function of incubation time was found in drug sensitive cells while an increase following decrease quercetin content was clearly demonstrated in both drug resistant cells (Fig. 1d).

The results of quercetrin partitioned into the cell pellets as a function of time was shown Fig. $1 \mathrm{~b}$ and e. Quercetrin was slightly partitioned into the cells suspended in RPMI 1640 medium while significantly increased in those cells suspended in HEPES-Na ${ }^{+}$ buffered solution. The similar results were obtained with rutin (Fig. 1c and f). It should be noted that both quercetrin and rutin were rapidly partitioned into the cells in both of cell suspended in RPMI 1640 and HEPES-Na ${ }^{+}$buffered solution. The concentration of quercetrin and rutin measured in cell pellets of HEPES$\mathrm{Na}^{+}$solution was $12 \pm 5$ nmole (per $4 \times 10^{6}$ cells), about 2.5 time higher degree than in the RPMI 1640 medium. 


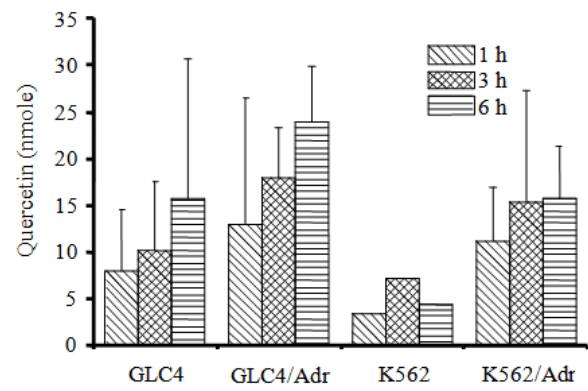

(a)
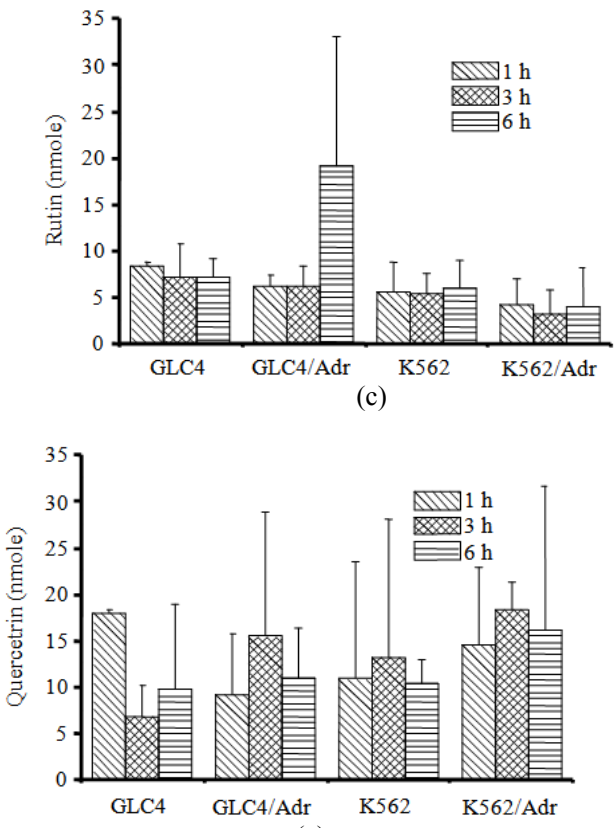

(e)

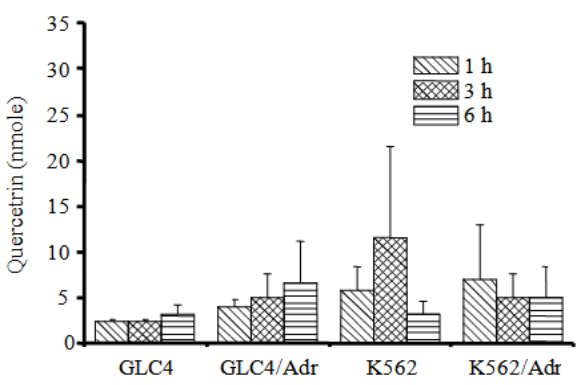

(b)

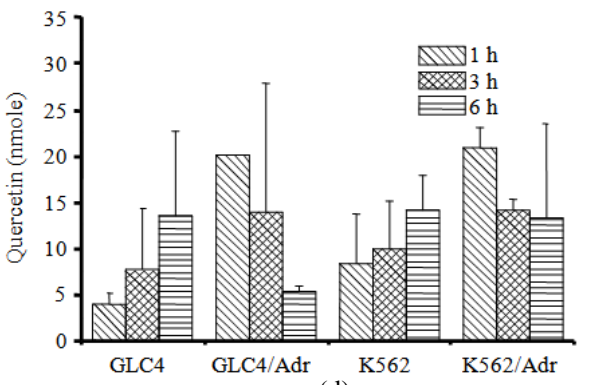

(d)

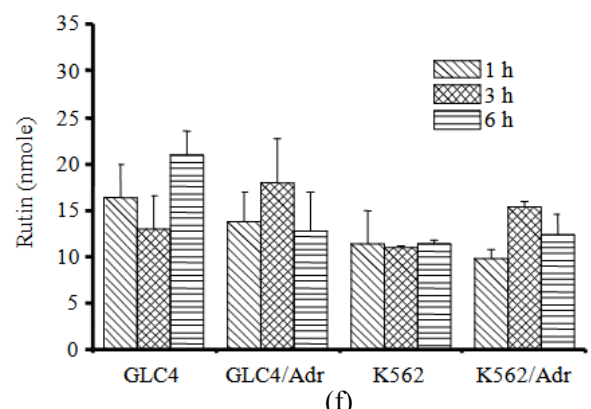

Fig. 1: The partition of quercetin, quercetrin and rutin into K562, K562/adr, GLC4 and GLC4/adr cells at the indicated incubation time; Cells $\left(4 \times 10^{6}\right)$ were suspended in $4 \mathrm{~mL}$ RPMI 1640 supplemented with $10 \%(\mathrm{v} / \mathrm{v})$ fetal calf serum (a, b and c) or HEPES-Na ${ }^{+}$buffered solution (d, e and f) without BSA pH 7.3 at $37^{\circ} \mathrm{C}$. The final concentration of molecules was $40 \mu \mathrm{M}$. The supernatant and cell pellets were separated at 1, 3 and $6 \mathrm{~h}$ after incubation. Data were mean $\pm \mathrm{SD}, \mathrm{n}=3$

It should be also noted that these molecules were found intact and stable in both extracellular and intracellular compartments during the experimental time period of study (at least $6 \mathrm{~h}$ ).

Cytotoxicity of quercetin, quercetrin and rutin: Quercetin similarly exhibited anticancer activity against K562, GLC4 and their corresponding multidrug resistant cells with $\mathrm{IC}_{50}$ values varied from $20-26 \mu \mathrm{M}$ (Table 1). The rhamnoside (quercetrin) and rutinoside (rutin) substituted molecule mediated higher efficacy than its parent compound in both K562 and GLC4 cells. Particularly, the rutinoside substitution exhibits 5-fold anticancer activity higher than quercetin. Contrary these substituted molecules caused lower sensitivity in multidrug resistant cells. As can be seen when $\mathrm{H}$-atom at $\mathrm{C} 3$ of ring $\mathrm{C}$ of quercetin was substituted by rutinoside the RF values were increased from 1-12 in K562/adr cells and from 1-15 in GLC4/adr cells.

Serum albumin protein is potential carrier and spontaneously and constantly releases flavonoids: The previous results indicated that BSA should act as binder of flavonoids thus influenced on their uptake by cells. We thus applied the spectrophotometric and FRET measurements for determining the microscopic and macroscopic binding constant of the complexation of BSA-molecules in our experimental conditions. 
Am. J. Biochem. \& Biotech., 7 (1): 10-20, 2011

Table 1: $\mathrm{IC}_{50}$ value of quercetin and its glycoside derivatives against K562 and GLC4 cells. RF is resistance factor defined as the IC50 of drugresistant cell divided by that of its corresponding drug-sensitive cells

\begin{tabular}{llllr}
\hline Compounds & $\mathrm{IC}_{50}(\mathrm{~K} 562), \mu \mathrm{M}$ & $\mathrm{RF}$ & $\mathrm{IC}_{50}(\mathrm{GLC} 4), \mu \mathrm{M}$ & $\mathrm{RF}$ \\
\hline Quercetin & $23.0 \pm 3.0$ & 1.0 & $18.0 \pm 8.5$ & 1.0 \\
Quercetrin & $11.0 \pm 0.00$ & 1.9 & $12.0 \pm 2.5$ & 4.8 \\
Rutin & $3.0 \pm 0.2$ & 11.6 & $4.0 \pm 0.0$ & 14.8 \\
\hline
\end{tabular}

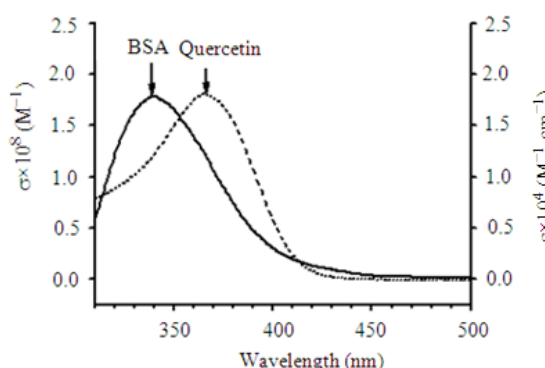

(a)

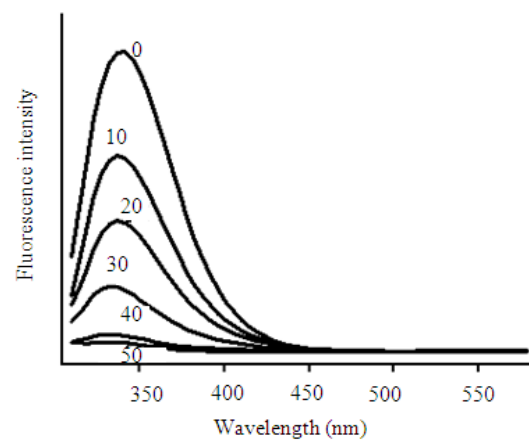

(c)

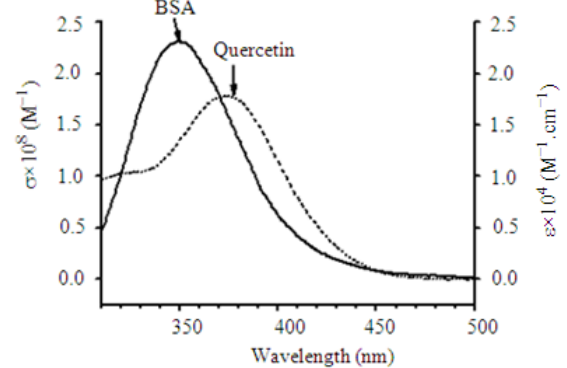

(b)

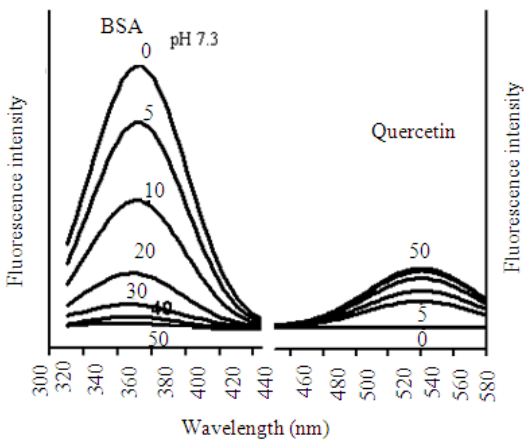

(d)

Fig. 2: The emission spectra of BSA and absorption spectra of quercetin measured in the HEPES-Na ${ }^{+}$buffered solution $\mathrm{pH} 4$ (a and c) and $\mathrm{pH} 7.3$ (b and d); BSA was dissolved in $2 \mathrm{~mL}$ HEPES-Na ${ }^{+}$buffered solution, $\mathrm{pH}$ 4 or 7.3 in $1-\mathrm{cm}$ quartz cuvette placed in the sample holder thermostated control at $37^{\circ} \mathrm{C}$. Steady-state fluorescence was recorded after addition the indicated concentration of molecule at using $10 \mathrm{~nm}$ and $10 \mathrm{~nm}$ or $2.5 \mathrm{~nm}$ and $5 \mathrm{~nm}$ excitation and emission slit widths, respectively.

Spectroscopic properties of BSA, quercetin, quercetrin and rutin: BSA is completely dissolved in HEPES-Na ${ }^{+}$buffered solution $\mathrm{pH} 4$ at $25^{\circ} \mathrm{C}$ up to $10^{-2}$ M. It possesses an emission spectrum with maximum fluorescence intensity at $340 \mathrm{~nm}$ when excited at 310 $\mathrm{nm}$ (Fig. 2a). However, the width at half height of the emission spectral shape become smaller and the maximum fluorescence intensity was 1.7 fold increase and this wavelength was shifted from 340-350 nm when the measurement was performed in the solution $\mathrm{pH} 7.3$ (Fig. 2b).

The absorption spectra of quercetin in HEPES-Na ${ }^{+}$ buffered solution $\mathrm{pH} 4$ and 7.3 at $37^{\circ} \mathrm{C}$ were shown in Fig. 1a and b. In HEPES-Na ${ }^{+}$buffered solution $\mathrm{pH} 4$, quercetin possessed an absorption spectrum between 250-500 nm composed of two absorption bands which has maximum absorbance at 274 and $370 \mathrm{~nm}$, respectively. It should be noted that the absorption spectral shape was changed when the measurement were performed in HEPES-Na ${ }^{+}$buffered solution $\mathrm{pH}$ 7.3; the width at half height of the peak became larger, the absorbance at $370 \mathrm{~nm}$ decreased and the maximum absorbance was shifted from at 370 to $390 \mathrm{~nm}$ (Fig. 2a and $b$ ). These signified that quercetin was ionized and should be presented in neutral and positive charge form (Tungjai et al., 2008). Similar results were obtained for quercetrin and rutin (Fig. 3).

Binding studies of quercetin, quercetrin and rutin with BSA: The binding of quercetin and its glycoside to BSA can be easily analyzed by using Fluorescence Resonance Energy Transfer (FRET). The overlay of an emission spectrum of albumin and an absorption spectrum of quercetin was indicated in Fig. $2 a$ and $b$. 


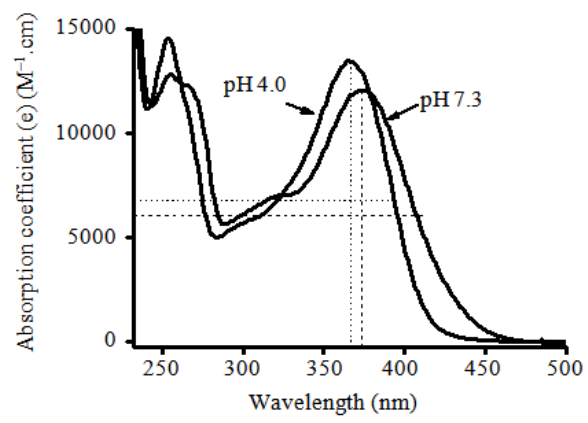

(a)

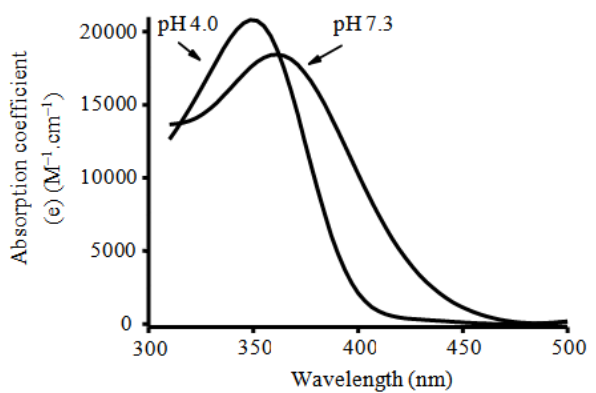

(b)

Fig. 3: The absorption spectra of quercetrin (a) and rutin (b). The stock of $0.1 \mathrm{M}$ quercetin or rutin was prepared in MDSO. The successive addition of the stock solution in $1 \mathrm{~cm}$ quartz cuvette containned $2 \mathrm{~mL}$ HEPES-Na ${ }^{+}$buffered solution $\mathrm{pH} 4$ or 7.3 placed in the sample holder thermostated control at $37^{\circ} \mathrm{C}$.

It is clearly demonstrated that BSA and quercetin can be served as donor and acceptor, respectively. BSA is excited at $310 \mathrm{~nm}$, by a long-range dipole-dipole coupling mechanism. This excited state is then nonradiatively transferred to quercetin or its derivative molecules. Thus BSA returns to the electronic ground state. The yield of FRET depends on two physical parameters including (1) the spectral overlap integral $\left(\mathrm{J}_{(\lambda)}\right)$ between BSA emission spectrum and quercetin absorption spectrum and (2) the critical transfer distance $\left(\mathrm{R}_{0}\right)$.

The typical results of the spectral overlap integral $\left(\mathrm{J}_{(\lambda)}\right)$ between the BSA emission spectrum and the quercetin absorption spectrum of the solution $\mathrm{pH} 4$ and 7.3 were indicated in Fig. $3 a$ and $b$, respectively. The $\mathrm{J}_{(\lambda)}$ can be calculated by using Eq. 1:

$$
J(\lambda)=\frac{\int_{0}^{\infty} F_{D} \varepsilon_{A} \lambda^{4} d \lambda}{\int_{0}^{\infty} F_{D} d \lambda}
$$

where, $F_{D}(\lambda)$ and $\varepsilon(\lambda)$ are represent the non-linear fit curve of fluorescence intensity from pure BSA and molar extinction coefficient of the quercetin respectively at the wavelength $\lambda$.

After integrating the equation 1; by varying the wave length $(\lambda)$ between $310-580 \mathrm{~nm}$, the $J(\lambda)$ was determined equal to $1.49 \times 10^{-14} \mathrm{M}^{-1} \cdot \mathrm{cm}^{3}$ in aqueous solution at $\mathrm{pH} 4$ and $2.39 \times 10^{-14} \mathrm{M}^{-1} \cdot \mathrm{cm}^{3}$ at $\mathrm{pH}$ 7.3 .

Figure $2 \mathrm{c}$ and $2 \mathrm{~d}$ showed the emission fluorescence spectra when excited at $310 \mathrm{~nm}$ recorded immediately after addition of varied concentrations of quercetin into the solution of BSA. All series of FRET experiments, the concentration of BSA was fixed to 3 and $5 \mu \mathrm{M}$ while the concentrations of quercetin were varied from 0.5-50 $\mu \mathrm{M}$. The complexation of BSA-quercetin can be clearly characterized by measuring the FRET fluorescence intensity at $540 \mathrm{~nm}$ (Fig. 2d) or extinction fluorescence intensity at $350 \mathrm{~nm}$ (Fig. 2c). As can seen in Fig. 2c and $d$ the FRET phenomenon can be measured only when the reactions were performed in the HEPES-Na ${ }^{+}$buffered solution $\mathrm{pH} 7.3$ in the presence of $3 \mu \mathrm{M}$ BSA. However, the extinction of BSA fluorescence intensity without appearance of FRET band was observed for the same reaction performed in HEPES-Na ${ }^{+}$buffered solution $\mathrm{pH} 4$ but the FRET can be measured in these conditions of experiments when increased in concentration of BSA such as $5 \mu \mathrm{M}$. In our conditions of experiments, the maximum of reaction product was obtained when 50 $\mu \mathrm{M}$ quercetin was used. These samples were used to estimate the FRET parameters between BSA and quercetin.

$\mathrm{R}_{\mathrm{o}}$ is defined as critical transfer distance at which the transfer efficiency equals $50 \%$ or the fluorescence of donor is quenched by $50 \% \mathrm{R}_{\mathrm{o}}$ is calculated by using the Eq. 2:

$$
\mathrm{R}_{0}=9790\left(\kappa^{2} \varphi_{0} \mathrm{Jn}^{-4}\right)^{\frac{1}{6}}
$$

Where:

$\mathrm{K}^{2}=$ The orientation factor between the emission of the dipole of the donor and the absorption dipole of the acceptor, which is generally $2 / 3$ for isotropic donor and acceptor

$\phi_{0}=$ The quantum yield of the donor $=0.101$ (Mishra et al., 2005)

$\mathrm{n}=$ The refractive index of the medium (phosphate buffer $\mathrm{pH} 7.3, \mathrm{n}=1.32$ (Mishra et al., 2005)

$\mathrm{J}=$ The spectral overlap integral between the donor emission spectrum and the acceptor absorption spectrum 
Am. J. Biochem. \& Biotech., 7 (1): 10-20, 2011

Table 2: The FRET and BSA-molecule complication parameters measured by using FRET analysis in the HEPES-Na ${ }^{+}$buffered solutions pH 4 and 7.3, the final concentration of BSA was fixed at $3 \mu \mathrm{M}$

\begin{tabular}{|c|c|c|c|c|c|c|c|}
\hline \multirow[b]{2}{*}{ Compounds } & \multicolumn{7}{|l|}{$\mathrm{pH}=4$} \\
\hline & $\mathrm{J}_{(\lambda)} \mathrm{M}^{-1} \cdot \mathrm{cm}^{3}$ & $\mathrm{R}_{0}, \AA$ & $\mathrm{r}, \AA \AA$ & $\mathrm{k}_{\mathrm{d} 1}, \mathrm{M}^{-1}$ & $\mathrm{k}_{\mathrm{d} 2} \mathrm{M}^{-1}$ & $\mathrm{~K}_{\mathrm{D}}, \mathrm{M}^{-1}$ & $\mathrm{n}$ \\
\hline Quercetin & $1.49 \times 10^{-14}$ & 55.38 & 34.98 & $3.5 \times 10^{-4}$ & $5.2 \times 10^{-7}$ & $1.75 \times 10^{5}$ & 1.70 \\
\hline Quercetrin & $1.10 \times 10^{-14}$ & 24.60 & 11.00 & $1.2 \times 10^{-4}$ & $3.1 \times 10^{-7}$ & $1.12 \times 10^{5}$ & 1.60 \\
\hline Rutin & $4.66 \times 10^{-14}$ & 31.13 & 19.05 & - & - & $5.00 \times 10^{4}$ & 1.00 \\
\hline \multicolumn{8}{|l|}{$\mathbf{P H}=7.3$} \\
\hline Compounds & $\mathrm{J}_{\mu} \mathrm{M}^{-1} \cdot \mathrm{cm}^{3}$ & $\mathrm{R}_{0,} \AA$ & $\mathrm{r}, \AA$ & $\mathrm{k}_{\mathrm{d} 1}, \mathrm{M}^{-1}$ & $\mathrm{k}_{\mathrm{d} 2}, \mathrm{M}^{-1}$ & $\mathrm{~K}_{\mathrm{D}}, \mathrm{M}^{-1}$ & $\mathrm{n}$ \\
\hline Quercetin & $2.39 \times 10^{-14}$ & 59.93 & 33.81 & $3.3 \times 10^{-4}$ & $4.76 \times 10^{-7}$ & $1.37 \times 10^{5}$ & 1.70 \\
\hline Quercetrin & $1.7 \times 10^{-14}$ & 26.20 & 13.50 & $1.4 \times 10^{-7}$ & $4.9 \times 10^{-7}$ & $1.66 \times 10^{5}$ & 1.60 \\
\hline Rutin & $9.14 \times 10^{-14}$ & 34.83 & 21.32 & - & - & $5 \times 10^{4}$ & 1.18 \\
\hline
\end{tabular}

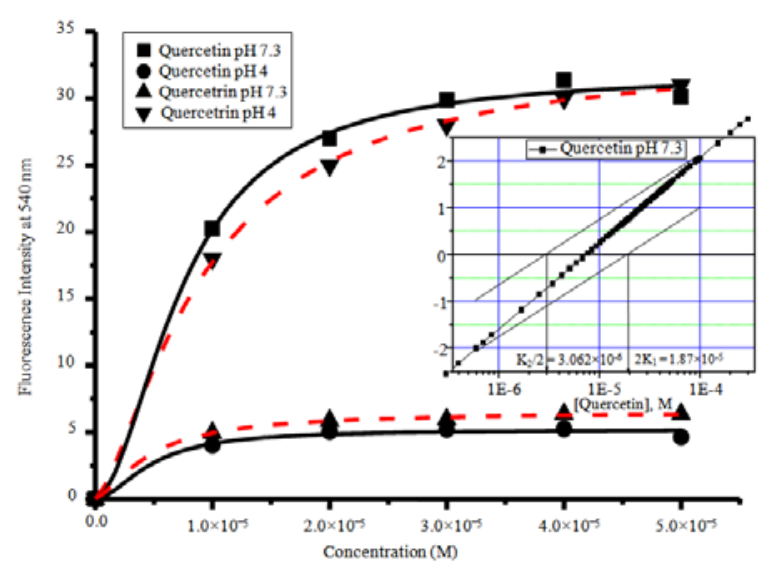

Fig. 4: FRET analysis of BSA-Quercetin and BSAQuercetrin complex as a function of their concentration [Results were obtained from the series of experiments with same conditions as Fig. 2; in set of Fig. 4. Hill's plot of $\log [v /(2-$ $v)$ ] as a function of log [quercetin] for binding of quercetin to BSA with two identical binding sites. The curves correspond to independent binding (--------) or cooperative binding (-) to the two sites with the indicated binding constants

The $\mathrm{R}_{0}$ of BSA-quercetin system determined was equal to $55.38 \AA$ at $\mathrm{pH} 4.0$ and equal to $59.93 \AA$ at $\mathrm{pH}$ 7.3.

Fig. 2d also shows that the fluorescence intensity at $540 \mathrm{~nm}$ (excited at $310 \mathrm{~nm}$ ) was immediately measured after addition of quercetin into the BSA solution. These signified that the complexation was immediately done and cannot be measured the kinetics of reaction by using our technique. The fluorescence intensity at 540 $\mathrm{nm}$ was increased then reached a pseudo plateau when the concentration of quercetin increased (Fig. 4). The data were fitted using Hill's equation yielding the Hill's number closed to 2 as indicated in Table 2, signifying a cooperative binding behavior and BSA has two binding sites for quercetin. The proposed mechanisms of BSAquercetin complication were done two steps as following:

$\mathrm{BSA}+\mathrm{Q}_{1} \rightleftharpoons \mathrm{BSA}-\mathrm{Q}_{1}$

$\mathrm{BSA}-\mathrm{Q}_{1}+\mathrm{Q}_{2} \rightleftharpoons \mathrm{Q}_{2}-\mathrm{BSA}-\mathrm{Q}_{1}$

The first Quercetin $\left(\mathrm{Q}_{1}\right)$ binds to the low affinity binding site with the microscopic binding constant $\left(\mathrm{k}_{\mathrm{d} 1}\right)$. This yields a conformation change of the second binding site, causing an increase in affinity to the second quercetin $\left(\mathrm{Q}_{2}\right)$, with the microscopic binding constant $\left(\mathrm{k}_{\mathrm{d} 2}\right)$. The experimental data should represent the fractional degree of saturation of the available protein binding sites for quercetin which can be expressed as $v=\frac{F}{C}$ where $F$ is the molar fluorescence intensity of complex and $\mathrm{C}$ is total concentration of BSA. When $v=0$ means that all BSA is in free form whereas a value of $v=2$ indicates that all binding sites of BSA are occupied with quercetin. In case of the stoichiometric complexation is 1 mole of BSA to 2 mole quercetin, the cooperative binding behavior can be characterized as the ratio of occupied sites (v) to unoccupied sites (2-v) which is given by $\frac{\left(v_{2}\right)}{\left(2-v_{2}\right)}=\frac{\left(k_{d 2} C+2 C^{2}\right)}{\left(2 k_{d 1} k_{2}+k_{d 2} C\right)}$. If we now plot the $\log [v /(2-$ $v)$ ] versus the $\log (\mathrm{C})$ we obtain the Hill's plot from which several parameters of the cooperative binding interaction can be determined and which is shown in inset of Fig. 4 and the $\mathrm{k}_{\mathrm{d} 1}$ and $\mathrm{k}_{\mathrm{d} 2}$ were determined as reported in Table 2.

Figure $2 \mathrm{c}$ and $2 \mathrm{~d}$ also allows calculating the efficiency of Energy transfer (E) from the BSA to the quercetin by using Eq. 3:

$$
\mathrm{E}=1-\frac{\mathrm{F}}{\mathrm{F}_{0}}
$$


Where:

$\mathrm{F}=$ fluorescence intensity of the BSA in the presence of $50 \mu \mathrm{M}$ quercetin

$\mathrm{F}_{0}=$ fluorescence intensity of the BSA in the absence of FRET

The E of BSA-quercetin system determined was equal to 0.94 at $\mathrm{pH} 4.0$ and equal to 0.97 at $\mathrm{pH} 7.3$.

In fact the efficiency of energy transfer (E) is related to the distance $r(\AA)$ between the donor and the acceptor as indicated in the Eq. 4:

$\mathrm{E}=\frac{\mathrm{R}_{0}^{6}}{\mathrm{R}_{0}^{6}+\mathrm{r}^{6}}$

where, $r$ is the distance between donor and acceptor in Angstrom unit.

The $r$ of BSA-quercetin system determined was equal to $34.98 \AA$ at $\mathrm{pH} 4.0$ and equal to $33.81 \AA$ at $\mathrm{pH}$ 7.3.

The FRET analysis in the similar conditions of experiments was performed with quercetrin and rutin. The FRET and BSA-molecule complication parameters were indicated in Table 2.

\section{DISCUSSION}

Quercetin and its glycoside derivatives present great interest as potential anticancer and anticarcinogenic molecules, unfortunately its very poor solubility and unstable in an aqueous solution that hampers the progression in clinical trials. This study clearly shows that BSA increased in the solubility of quercetin, quercetrin qnd rutin in both RPMI 1640 medium and HEPES-Na ${ }^{+}$buffer solution. BSA found in the culture medium can serve as a carrier and spontaneously and constantly release source of flavonoids particular quercetin in vitro cytotoxicity assay. It was clearly shown that the complexation of BSA with quercetin, quercetrin and rutin was immediately done after addition the compounds into the BSA solutions. We rigorously determined the crucial parameters including the macroscopic and microscopic rate constant of binding of the complex by using FRET analysis. The ratio of complexation was 1 mole of BSA to 2 moles of quercetin and quercetrin. At $\mathrm{pH} 7.3$, the $\mathrm{K}_{\mathrm{D}}$ value was $1.37 \times 10^{5} \mathrm{M}^{-1}$ for BSA-quercetrin and $1.68 \times 10^{5} \mathrm{M}^{-1}$ for BSA-quercetin. These results should be interpreted as the BSA-quercetrin complex is higher stability than the BSA-quercetin. As a consequence quercetrin was significantly found lower degree than quercetin in cell pellets of the series using RPMI 1640 medium. The rutinoside substitution caused a change in the ratio of BSA-rutin complexation $(1: 1)$ signifying that the rutinoside affected the molecular steric of quercetin thus changed the behavior of interaction with BSA. Moreover, the $\mathrm{K}_{\mathrm{D}}$ value of the BSA-rutin was equal to $5.0 \times 10^{4} \mathrm{M}^{-1}$. In fact among the compounds studied, the BSA-rutin is the most stable and the cellrutin concentration is very low compared with quercetin and quercetrin.

The study clearly demonstrated that BSA affected the cellular uptake of quercetin glycoside. Since the cellular uptake of quertin in HEPES-Na ${ }^{+}$buffered and RPMI 1640 was almost the same, this signified that BSA can improve the dissolubility of quercetin and can act as a suitable carrier of quercetin by which spontaneously release the quercetin to the solution and cells. Let consider the effects of the glycoside moiety on the behavior and reactivity of the molecules. The esterification of 3-rhamnoside at C3, particularly the 3rutinoside rendered the molecules to have higher affinity to BSA and considerably increased in stability of the complexes. This should be the predominant cause of very low concentration of rutin found in the cell pellets.

The cytotoxicity results clearly showed that rhamnoside and rutinoside substituted molecules mediated higher efficacy than its parent compound in both K562 and GLC4 cells. Particularly, the rutinoside substitution exhibits 5-fold anticancer activity higher than quercetin. Indeed, it is known that quercetin mediated anticancer action at the mitochondrial level triggering particular various cancer cell types to be suicide the so-called "apoptosis" (Samanta and Bhattacharya, 2010; Choiprasert et al., 2010; Kothan et al., 2004; Dechsupa et al., 2007; Li et al., 2007; Ramanouskaya et al., 2009). The efficacy of apoptosis induction of quercetin depends upon its intracellular target concentration. These results suggested that the BSA-quercetrin and BSA-rutin complexes might change the specific target and cellular distribution pattern. We hypothesized that both BSA-quercetrin and BSA-rutin complexes might mediated anticancer action via an interaction with the extrinsic pathway, activated by pro-apoptotic receptor signals at the cellular surface.

\section{CONCLUSION}

BSA can considerably improve the solubility of quercetin and its glycoside derivatives, in particularly these flavonoids have high affinity to BSA. Among the compounds studied, the BSA-rutin is the most stable and the cell-rutin concentration is very low compared with quercetin and quercetrin. The subsititution of rhamnoside and rutinoside at $\mathrm{C} 3$ in particular the 
rutinoside yields an increase in complex stability by $\sim 29$-fold compared with quercetin. The macroscopic binding constant was directly influenced on the cellular uptake of molecules. This study reported for the first time the suitable range of binding constant $\left(\mathrm{K}_{\mathrm{D}} \geq\right.$ $10^{5} \mathrm{M}^{-2}$ ) of the carrier-drug by which the carrier can be useful for increasing the solubility of drug and also spontaneously release the drug into the solution and cells. As a consequence the complication did not change in the mode of action of molecule. Contrary, an increase in complex stability by 29 -fold caused dramatically decreased in the cellular concentration such as the case of rutin. It should be expected that the available cytosolic concentration might not be enough to mediate any biological effects but the complex might directly interact with the pro-apoptotic receptor signals at surface membrane of cells.

\section{ACKNOWLEDGEMENT}

WC would like to thank the ministry of education for financial support. This work was financially supported by a grant funded under the Strategic Scholarships for Frontier Research Network for the Government, the Office of the Higher Education Commission (OHEC), Ministry of Education Thailand.

\section{REFERENCES}

Ayudhya, N.S.N. and S. Mankhetkorn, 2009. Diatrizoate, Iopromide and Iotrolan Enhanced Cytotoxicity of Daunorubicin in Multidrug Resistant K562/adr Cells: Impaired the Mitochondrial and Inhibited the P-Glycoprotein Function. Am. J. Applied Sci., 6: 484-491. DOI: 10.3844/ajassp.2009.484.491

Choiprasert, W. and S. Mankhetkorn, 2006. Fluorescence resonance energy transfer study of quercetin and quercetrin interaction with bovine serum albumin in physiological solution: Determination of binding constants and binding sites. Proceeding of the 32nd Congress on Science and Technology of Thailand (STT.32), pp: 320. ISBN: 974-229-963-3

Choiprasert, W., N. Dechsupa, S. Kothan, M. Garrigos and S. Mankhetkorn, 2010. Quercetrin except rutin potentially increased pirarubicin cytotoxicity by non-competitively inhibiting the P-glycoproteinand MRP1 function in living K562/adr and GLC4/adr cells. Am. J. Pharmaco. Toxicol., 5: 24-33. DOI: 10.3844/ajptsp.2010.24.33

Dangles, O., C. Dufour and S. Bret, 1999. Flavonoserum albumin complexation. Two-electron oxidation of flavonols and their complexes with serum albumin. J. Chem. Soc. Perkin Trans., 2: 737-744. DOI: $10.1039 / \mathrm{A} 901460 \mathrm{H}$
Dechsupa S., S. Kothan, J. Vergote, G. Leger and A. Martineau et al., 2007. Quercetin, Siamois 1 and Siamois 2 Induce Apoptosis in Human Breast Cancer MDA-MB-435 Cells Xenograft in vivo. Cancer Bio. Therapy, 6: 56-61. DOI: 10.4161/cbt.6.1.3548

Dechsupa, N. and S. Mankhetkorn, 2009. PGlycoprotein-Mediated efflux and drug sequestration in lysosomes confer advantages of k562 multidrug resistance sublines to survive prolonged exposure to cytotoxic agents. Am. J. Applied Sci., 6: 1637-1646. DOI: 10.3844/ajassp.2009.1637.1646

Dufour, C. and O. Dangles, 2005. Flavonoid-serum albumin complication: Determination of binding constants and binding sites by fluorescence spectroscopy. Biochim. Biophys. Acta, 1721: 164-173. DOI: 10.1016/j.bbagen.2004.10.013

Garnier-Suillerot, A., C. Marbeuf-Gueye, M. Salerno, C. Loetchutinat and I. Fokt et al., 2001. Analysis of drug transport kinetics in multidrug-resistant cells: Implications for drug action. Curr. Med. Chem., 8: 51-64. PMID: 11172692

Hertog, M.G., P.M. Sweetnam, A.M. Fehily, P.C. Elwood and D. Kromhout, 1997. Antioxidant flavonols and ischemic heart disease in a Welsh population of men: the Caerphilly Study. Am. J. Clin. $\quad$ Nutr., 65: 1489-1494. http://www.ajen.org/content/65/5/1489.full.pdf + ht $\mathrm{ml}$

Hirvonen, T., P. Pietinen, M. Virtanen, M.L. Ovaskainen and S. Hakkinen et al., 2001. Intake of flavonols and flavones and risk of coronary heart disease in male smokers. Epidemiology, $\quad 12$ : $\quad 62-67$. http://www.jstor.org/stable/3703680

Iwanaga, K., T. Kushibiki, M. Miyazaki and M. Kakemi, 2006. Disposition of lipid-based formulation in the intestinal tract affects the absorption of poorly water-soluble drugs. Biol. Pharm. Bull., 29: 508-512. DOI: 10.1248/bpb.29.508

Jones, M.C., H. Gao and J.C. Leroux, 2008. Reverse polymeric micelles for pharmaceutical applications. J. Control Release, 132: 208-215. DOI: 10.1016/j.jconrel.2008.05.006

Kitson, T.M., 2004. Spectrophotometric and kinetic studies on the binding of the bioflavonoid quercetin to bovine serum albumin. Biosci. Biotechnol. Biochem., 68: 2165-2170. DOI: 10.1271/bbb.68.2165 
Knekt, P., J. Kumpulainen, R. Jarvinen, H. Rissanen and M. Heliovaara et al., 2002. Flavonoid intake and risk of chronic diseases. Am. J. Clin. Nutr. 76: 560-568. http://www.ajcn.org/content/76/3/560.full.pdf + htm 1

Kothan, S., S. Dechsupa, J.L. Moretti, J. Vergote and S. Mankhetkorn, 2004. Spontaneous mitochondrial membrane potential change during apoptotic induction by quercetin in K562 and K562/R cells. Can. J. Physiol. Pharmacol., 82: 1084-1090. DOI: 10.1139/Y04-113

Kratz, F., 2008. Albumin as a drug carrier: Design of prodrugs, drug conjugates and nanoparticles. J. Controlled Release, 132: 171-183. DOI: 10.1016/j.jconrel.2008.05.010

Li, Y., H. Fang and W. Xu, 2007. Recent advance in the research of flavonoids as anticancer agents. Mini Rev. Med. Chem. 7: 663-678. PMID: 17627579

Lupidi, G., A. Scire, E. Camaioni, K.H. Khalife and G. De Sanctis et al., 2010. Thymoquinone, a potential therapeutic agent of Nigella sativa, binds to site I of human serum albumin. Phytomedicine, 17: 714-720. DOI: 10.1016/j.phymed.2010.01.011

Mink, P.J., C.G. Scrafford, L.M. Barraj, L. Harnack and C.P. Hong et al., 2007. Flavonoid intake and cardiovascular disease mortality: A prospective study in postmenopausal women. Am. J. Clin. Nutr., 85: 895-909. http://www.ajcn.org/content/85/3/895.full.pdf + htm 1

Mishra, B., A. Barik, K.I. Priyadarsini and H. Mohan, 2005. Fluorescence spectroscopic studies on binding of a flavonoid antioxidant quercetin to serum albumins. J. Chem. Sci., 117: 641-647. DOI: 10.1007/BF02708293

Moriyama, Y., D. Ohta, K. Hachiya, Y. Mitsui and K. Takeda, 1996. Fluorescence behavior of tryptophan residues of bovine and human serum albumins in ionic surfactant solutions: A comparative study of the two and one tryptophan(s) of bovine and human albumins. J. Protein Chem., 15: 265-272. DOI: 10.1007/BF01887115

Nia, Y., X. Zhang and S. Kokot, 2009. Spectrometric and voltammetric studies of the interaction between quercetin and bovine serum albumin using warfarin as site marker with the aid of chemometrics. Spectrochimica Acta Part A., 71: 1865-1872. DOI: 10.1016/j.saa.2008.07.004

Nijveldt, R.J., E. Van Nood, D.E.C. Van Hoorn, P.G. Boelens and K. van Norren et al., 2001.
Flavonoids: A review of probable mechanisms of action and potential applications. Am. J. Clin. Nutrit., $\quad 74$ : 418-425. http://www.ajcn.org/content/74/4/418.full.pdf + htm 1

Ramanouskaya, T.V., V.V. Smolnykova and V.V. Grinev, 2009. Relationship between structure and antiproliferative, proapoptotic and differentiation effects of flavonoids on chronic myeloid leukemia cells. Anticancer Drugs, 20: 573-583. DOI: 10.1097/CAD.0b013e32832d684c

Rimm, E.B., M.B. Katan, A. Ascherio, M.J. Stampfer and W.C. Willett, 1996. Relation between intake of flavonoids and risk for coronary heart disease in male health professionals. Ann. Intern. Med., 125: 384-389. http://www.annals.org/content/125/5/384.full.pdf

Samanta, S.K. and K. Bhattacharya, 2010. Identification and quantification of the active component quercetin 3-O-rutinoside from Barringtonia racemosa, targets mitochondrial apoptotic pathway in acute lymphoblastic leukemia. J. Asian Natural Products Res., 12: 639-648. ISSN: 1477-2213

Tian, J., J. Liu, W. He, Z. Hu, X. Yao and X. Chen, 2004. Probing the binding of scutellarin to human serum albumin by circular dichroism, fluorescence spectroscopy, FTIR and molecular modeling method. Biomacromolecules, 5: 1956-1961. DOI: $10.1021 / \mathrm{bm} 049668 \mathrm{~m}$

Tungjai, M., W. Poompimon, C. Loetchutinat, S. Kothan and N. Dechsupa et al., 2008. Spectrophotometric characterization of behavior and the predominant species of flavonoids in physiological buffer: Determination of solubility, lipophilicity and anticancer efficacy. Open Drug Deliv. $\quad$ J., $\quad$ 2: 10-19. http://www.benthamscience.com/open/toddj/article s/V002/10TODDJ.pdf

Varshney, A., P. Sen, E. Ahmad, M. Rehan and N. Subbarao et al., 2010. Ligand binding strategies of human serum albumin: How can the cargo be utilized? CHIRALITY, 22: 77-87. DOI: 10.1002/chir.20709

Wang, L., Y.C. Tu, T.W. Lian, J.T. Hung and J.H. Yen et al., 2006. Distinctive Antioxidant and Antiinflammatory Effects of Flavonols. J. Agric. Food Chem., 54: 9798-9804. DOI: 10.1021/jf0620719 
Watanabe, M., K. Kawano, K. Toma Y. Hattori and Y. Maitani, 2008. In vivo antitumor activity of camptothecin incorporated in liposome's formulated with an artificial lipid and human serum albumin. J. Control Release, 127: 231-238. DOI: 10.1016/j.jconrel.2008.02.005

Yochum, L., L.H. Kushi, K. Meyer and A.R. Folsom, 1999. Dietary flavonoid intake and risk of cardiovascular disease in postmenopausal women. Am. J. Epidemiol., 149: 943-949. http://aje.oxfordjournals.org/content/149/10/943.ful 1.pdf + html
Yue, Y., X. Chen, J. Qin and X. Yao, 2009. Spectroscopic investigation on the binding of antineoplastic drug oxaliplatin to human serum albumin and molecular modeling. Colloids Surf. B Biointerfaces, 69: 51-57. DOI: 10.1016/j.colsurfb.2008.10.016 